\title{
Water-Soluble Pressure-Sensitive Adhesives Containing Carboxymethyl Starch with Improved Adhesion to Paper
}

\author{
Katarzyna Wilpiszewska ${ }^{1}$ Zbigniew Czech $^{2}$
}

Published online: 13 June 2017

(C) The Author(s) 2017. This article is an open access publication

\begin{abstract}
Water-soluble pressure-sensitive adhesives (PSA) based on acrylic acid and carboxymethyl starch (CMS) have been prepared. The tack and peel adhesion to various paper types (newsprint, hygienic, packing, fax and art paper) as well as dynamic shear adhesion at higher temperatures $\left(70-240^{\circ} \mathrm{C}\right)$ have been tested with the aim of applying such PSA in a form of double-sided splicing tapes for paper industry. For all paper types tested tack and peel adhesion values increased with CMS content (0.1-10 wt\% in PSA). The highest tack and peel adhesion values (for the system containing $10 \mathrm{wt} \% \mathrm{CMS}$ ) were noted for fax paper ca. $19.5 \mathrm{~N} / 2.5 \mathrm{~cm}$ and $18.3 \mathrm{~N} / 2.5 \mathrm{~cm}$, respectively and the lowest ones for art paper: $14.7 \mathrm{~N} / 2.5 \mathrm{~cm}$ and $13.5 \mathrm{~N} / 2.5 \mathrm{~cm}$, respectively. Obtained PSA were completely soluble in water, and the time of water-solubility depended on CMS content, as well as $\mathrm{pH}$ value, however it did not exceed $5 \mathrm{~min}$.
\end{abstract}

Keywords Adhesives - Carboxymethyl starch · Polysaccharide $\cdot$ Pressure-sensitive adhesives $\cdot$ Watersoluble polymers

Katarzyna Wilpiszewska

kwilpi@zut.edu.pl

1 Faculty of Chemical Technology and Engineering, Polymer Institute, West Pomeranian University of Technology, ul. Pulaskiego 10, 70-322 Szczecin, Poland

2 Faculty of Chemical Technology and Engineering, Institute of Organic Chemical Technology, West Pomeranian University of Technology, ul. Pulaskiego 10, 70-322 Szczecin, Poland

\section{Introduction}

Papermaking and printing operations require splicing the end of one paper roll to the beginning of another one, as well as splicing together a roll after defective material is cut out. It is important that such splices could be made quickly and easily with the aid of adhesive that rapidly attains maximum strength and retains it throughout subsequent operations. In the era where ecology and conservation are both vital concerns, it is important that the spliced portions should be returnable to the paper mill for reprocessing, thus it is essential that the splices (and in particularly the adhesive applied) should be water-dispersible and repulpable. This combination of requirements hinders using conventional adhesives such as rubber-resin pressure-sensitive ones.

Water-soluble adhesives are known in the art of natural products, i.e.: dextrin, gelatin, casein or starch [1] or in the art of synthetic products, i.e.: poly(vinyl alcohol) or poly(vinyl pirrolidone) [2]. However, under dry conditions this type of products lacks elasticity and viscosity, showing no pressure-sensitive adhesive properties. Additionally, the conventional water-soluble adhesives exhibit disadvantages such as little thermal strength and little resistance to ageing. The range of potentially suitable synthetic polymers is also very limited. On the one hand a large number of natural or synthesized polymers, by their nature, exhibit no adhesive properties, whilst on the other hand, the adhesive tapes industry aims to raw materials which are produced in large quantities and at low cost. It is not necessary to develop new base polymers, but rather specifically modify the polymers selected according to commercial criteria. An unusual and interesting challenge is giving to pressure-sensitive adhesive some water-solubility, which depends greatly on the 
hydrophilicity of the groups incorporated into the polymer chain. The most often used hydrophilic monomers for synthesis of water-soluble acrylic PSA are: acrylic acid, methacrylic acid, $\beta$-acryloyloxypropionic acid and 2-hydroxypropyl acrylate [3-6].

Starch is inexpensive, biodegradable and renewable polysaccharide. There are some reports on using starchbased films as carriers for double-sided pressure-sensitive tapes for paper industry [7, 8]. There are known adhesives based on starch [9-12]. Carboxymethylated starch, due to introduction of bulky hydrophilic groups exhibits reduced tendency to retrogradation (recrystallinity), higher $\mathrm{pH}$ stability as well as is less prone to damages caused by heat and microbial attack when compared to native starch [13]. The physiochemical properties of carboxymethyl starch (CMS) depend on its degree of substitution (DS, the average number of $\mathrm{OH}$ groups substituted in recurrent unit). The solubility in cold water increases with DS value [14]. Moreover, water absorption, adhesiveness and film forming ability increases [15]. Zhou et al. [16] used highly substituted CMS as the main foundry adhesive. Although CMS is commonly used in many industrial areas (pharmacy, food, paper and textile industry) the authors are not familiar with any report on using CMS for PSA applications. However, there are some reports on preparing CMS-based wood adhesive containing poly(vinyl alcohol) and polyisocyanates [17] or using other carboxymethylated polysaccharide derivative, i.e. carboxymethyl cellulose (CMC) for starch-based wood adhesives [18] or polyisobutylene/CMC pressuresensitive adhesives [19].

In this paper novel water-soluble acrylic pressure-sensitive adhesives containing carboxymethyl starch, and subsequently preparation of double-sided self-adhesive splicing tape for paper industry has been proposed. The effect of CMS content on tack and peel adhesion to various paper types (newsprint, hygienic, packing, fax and art paper) as well dynamic shear adhesion at higher temperatures have been tested. Moreover, the solubility/dispersibility in water has been determined.

\section{Experimental}

\section{Raw Materials for Carboxymethyl Starch Preparation}

Potato starch was purchased from Nowamyl S.A., Nowogard (Poland). Monochloroacetic acid (a.g. Chempur, Poland) was used as etherifying agent, isopropanol (pure, Chempur) as a reaction medium. Sodium hydroxide (microgranules), and acetic acid, were the products of Chempur (Poland).
Raw Materials for Synthesis and Modification of Water Soluble Acrylic PSA

All industrially raw materials which were used for the synthesis and modification of water-soluble pressure-sensitive adhesives (PSA) based on acrylics were presented in Table 1.

\section{Preparation of CMS with High Degree of Substitution}

Preparing CMS with high degree of substitution 0.9 was carried out according to method reported elsewhere [20]. Starch was etherified in isopropanol/water as a one-step process. Monochloroacetic acid was dissolved with isopropanol in reactor, and then $\mathrm{NaOH}$ water solution was added. When the mixture became white and homogenous, $30 \mathrm{~g}$ starch (13.6-14.0 wt\% moisture) and remaining part of $\mathrm{NaOH}$ microgranules were introduced. Reaction was performed for $2.5 \mathrm{~h}$ at $50^{\circ} \mathrm{C}$. The obtained product was filtered, neutralized with glacial acetic acid, washed five times with $80 \mathrm{wt} \%$ methanol, once with methanol and dried in the air, leaving on the warm surface.

\section{Synthesis of Poly(Acrylic Acid)}

The synthesis of poly(acrylic acid) (PAA) was conducted with $40 \mathrm{wt} \%$ polymer concentration in polymerization mixture of $90 \mathrm{wt} \%$ demineralized water and $10 \mathrm{wt} \%$ isopropanol in the presence of $0.1 \mathrm{wt} \%$ radical initiator azobisisobutyronitrile (AIBN) on a basis of polymer amount. After dosing monomer (acrylic acid, for $2 \mathrm{~h}$ ) to the boiled solvent mixture $4 \mathrm{~h}$ post-reaction time for reducing acrylic acid residue has been performed. The viscosity and molecular weights of synthesized PAA has been determined.

\section{Viscosity and Molecular Weight of Synthesized PAA}

The viscosity of the synthesized PAA was determined with Rheomat RM 189 from Rheomatric Scientific, with spindle No 3 at $23^{\circ} \mathrm{C}$.

The molecular weight studies were performed in tetrahydrofurane with a liquid chromatography LaChrom system: RI Detector L-7490 and LaChrom UV Detector L-7400 from Merck-Hitachi, equipped with a PLgel $10^{6} \AA$ column from Hewlett-Packard. The weights average molecular weight $M_{W}$, the number average molecular weight $M_{n}$ and the distribution of molecular weight, known as polydispersity $\mathrm{P}_{\mathrm{d}}$ were evaluated. 
Table 1 Raw materials used for synthesis and modification of water soluble acrylic PSA

\begin{tabular}{|c|c|c|}
\hline Trade name (Producer) & Abbreviation and chemical structure & Function \\
\hline Acrylic acid (BASF) & $\stackrel{\mathrm{AA}}{\stackrel{\mathrm{O}}{\|}} \mathrm{CH}_{2}=\mathrm{CH}-\stackrel{\mathrm{C}}{\mathrm{C}}-\mathrm{OH}$ & Monomer \\
\hline Vazo 65 (Du Pont) & 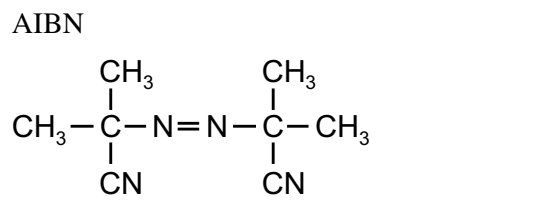 & Radical initiator \\
\hline Aluminium acetylacetonate (Wacker Chemie) & 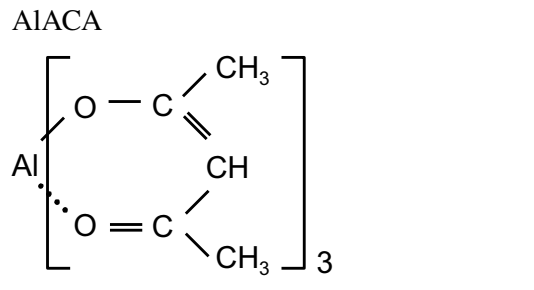 & Crosslinker (Wacker Chemie) \\
\hline Ethoduomeen T/25 (Akzo Chemie) & $\begin{array}{l}\mathrm{N}, \mathrm{N}^{\prime}, \mathrm{N}^{\prime} \text {-Polyoxy- } \\
\text { ethylene }(10) \mathrm{N} \text {-faty-1,3- } \\
\text { diamine propane } \\
\begin{array}{l}\mathrm{R}-\mathrm{N}-\left(\mathrm{CH}_{2}\right)_{3}-\mathrm{N}^{\prime} \\
\quad\left(\mathrm{C}_{2} \mathrm{H}_{4} \mathrm{O}\right)_{x} \mathrm{H} \\
\quad\left(\mathrm{C}_{2} \mathrm{H}_{4} \mathrm{O}\right)_{z} \mathrm{H}\end{array}\end{array}$ & Neutralized agents (Akzo Chemie) \\
\hline Pluriol 300 (BASF) & $\begin{array}{l}\text { PEG } 300 \\
\text { Polyethylene glycol with average molecular } \\
\text { weight of } 300 \mathrm{~g} / \mathrm{mol} \\
\mathrm{HO} \underset{\mathrm{CH}}{\mathrm{CH}}-\mathrm{CH}_{2}-\mathrm{O}_{\mathrm{n}} \mathrm{H} \\
\quad \mathrm{CH}_{3}\end{array}$ & Water-soluble plasticizer \\
\hline
\end{tabular}

The viscosity, molecular weight and polydispersity of synthesized water-soluble acrylic polymer were collected in Table 2.

\section{Preparation of Water-Soluble Acrylic Pressure-Sensitive Adhesives Containing CMS}

The water-based pressure-sensitive adhesives were prepared by blending, in order, the resulting polymer, crosslinker, plasticizer and the neutralizing agent. The $40 \mathrm{wt} \%$ acrylic polymer was modified according to polymer amount with $0.8 \mathrm{wt} \%$ crosslinking agent aluminum acetylacetonate (AlACA), $160 \mathrm{wt} \%$ polyethylene glycol with average molecular weight of 300 (Pluriol 300) and $100 \mathrm{wt} \%$ ethoxylated diamine Ethoduomeen T/25 to achieve completely water-soluble pressure-sensitive adhesive.

Table 2 Important parameters of synthesized PAA

\begin{tabular}{llll}
\hline Viscosity [Pa $\cdot \mathrm{s}]$ & $\mathrm{M}_{\mathrm{w}}[$ Dalton $]$ & $\mathrm{M}_{\mathrm{n}}[$ Dalton $]$ & $\mathrm{P}_{\mathrm{d}}=\mathrm{M}_{\mathrm{w}} / \mathrm{M}_{\mathrm{n}}$ \\
\hline 18.7 & 711,000 & 229,000 & 3.1 \\
\hline
\end{tabular}

Eventually, prepared PSA were mixed with 2 wt $\%$ CMS aqueous solution to obtain PSA formulation containing 0.1 , $1,3,5,8$ and $10 \mathrm{wt} \%$ of polysaccharide derivative basing on the acrylic polymer content.

\section{Preparing of Double-Sided Splicing Tapes}

Water-soluble modified acrylic PSA containing CMS were coated with $60 \mathrm{~g} / \mathrm{m}^{2}$ coat weight on dehesive silicon paper dried for $10 \mathrm{~min}$ at $110^{\circ} \mathrm{C}$ in drying canal and subsequently transferred under pressure on water-dispersible paper used as carrier. The resulted double-sided self-adhesive splicing tapes were tested on tack and peel adhesion to newsprint, hygienic, packing, fax and art paper, and dynamic shear adhesion at higher temperatures.

\section{Testing the Properties of Self-Adhesive Tapes}

Comprehensive testing of the splicing tapes containing modified water-soluble PSA with CMS and water dispersible paper carrier was intended to underpin their balanced 
performance level for application in the paper industry. The splicing tapes were tested and assessed according to the following criteria, amongst others:

- Tack, peel adhesion and dynamic shear adhesion at high temperatures;

- Water solubility (dispersibility) at $\mathrm{pH}=7,9$ and 11 .

\section{Tack, Peel Adhesion and Dynamic Shear Strength}

The resulted biodegradable self-adhesive tapes were investigated for typical PSA properties, such as tack peel adhesion and shear strength by standard A.F.E.R.A. (Association des Fabricants Europeens de Rubans Auto-Adhesifs) procedures. The details could be found in AFERA 4015 (tack), AFERA 4001 (peel adhesion), and PSTC-7 (dynamic shear adhesion).

Tack of pressure-sensitive adhesives is the adhesive property related to bond formation. Generally, the test procedure to measure tack consists of two steps: bond formation and bond separation and have to be measured at low contact pressures and short contact times. Tack method measures the instantaneous adhesion of a loop of adhesivecoated material using no external pressure to secure contact. According to another definition the quick stick tack value is the force required to separate at a specific rate a loop of material, which was brought into contact with a standard surface. The tack method according to AFERA 4015 is relatively simple and may be carried out using common tensile strength test machines. A sample of PSAcoated material 1 inch (about $2.5 \mathrm{~cm}$ ) wide and about 7 inch (about $17.5 \mathrm{~cm}$ ) long is bonded to a vertical of a steel plate covered firmly with one of the tested paper type at least 10 lineal $\mathrm{cm}$ in firm contact. The vertical steel test plate is clamped in the jaws of a Zwick/Roell 1.0 tensile testing machine. The scale reading in Newton is recorded as the tape is peeled from the steel surface with a constant rate of $100 \mathrm{~mm} / \mathrm{min}$.

Peel adhesion is the force required to remove a coated flexible pressure-sensitive adhesive sheet material from a test panel measured at a specific angle and rate of removal. For $180^{\circ}$ peel measurements (AFERA 4001) the results depend on the face stock material. A sample of PSA-coated material 1 inch (about $2.5 \mathrm{~cm}$ ) wide and about 5 inch (about $12.7 \mathrm{~cm}$ ) long is bonded to a horizontal target substrate surface of a steel plate covered firmly with one of the tested paper type at least $12.7 \mathrm{~cm}$ in firm contact. A $2 \mathrm{~kg}$ hard rubber roller is used to apply the strip. The free end of the coated strip is doubled back nearly touching itself so the angle of removal will be $180^{\circ}$. The free end is attached to the adhesion tester scale. The steel test plate is clamped in the jaws of a tensile testing machine, which is capable of moving the plate away from the scale at a constant rate of $300 \mathrm{~mm} / \mathrm{min}$. The scale reading in Newton is recorded as the tape is peeled from the steel surface. The data is reported as the average of the range of numbers observed during the test. The given result is an arithmetic average from the available peel adhesion results.

Dynamic shear adhesion was measured using a $2.5 \mathrm{~cm} \times 2.5 \mathrm{~cm}$ end portion of a $2.5 \mathrm{~cm} \times 15 \mathrm{~cm}$ strip of tape, formed by coating a $25 \mu \mathrm{m}$ thick layer of adhesive on one of the tested paper type adhered to a bright annealed steel test panel and rolled down with two passes of a $2 \mathrm{~kg}$ roller. The panel is then clamped in a jig which is disposed at $2^{\circ}$ to the vertical, so that the $12.5 \mathrm{~cm}$ free end of the tape extends downward, at an angle of $178^{\circ}$ to the test panel, and a 1000 gram weight is attached to the tape end. The shear strength was tested at temperature increasing from 70 to $240^{\circ} \mathrm{C}$. It was measured until the tape separated from the panel and was reported to the nearest minute. Further details are found in the aforementioned Test Methods for Pressure-Sensitive Tapes, Test PSTC-7. For water-soluble tapes is desirable to have shear time as high as possible, preferably exceeding 100 min, although an extremely tacky adhesive may be satisfactory if its shear time is between 10 and $40 \mathrm{~min}$.

\section{Water Solubility (Dispersibility)}

Water solubility (dispersibility) test (related to watersoluble pressure-sensitive adhesives) was determined at three $\mathrm{pH}$ values $(\mathrm{pH}=7, \mathrm{pH}=9$ and $\mathrm{pH}=11)$. The $1 \mathrm{~m} \times 1 \mathrm{~m}$ linen drape was coated with $1 \mathrm{~cm} \times 10 \mathrm{~cm}$ samples of prepared pressure-sensitive adhesives. The drape was folded in a such a way that the tape was stuck to two sides of the drape. The drape was then folded twice and

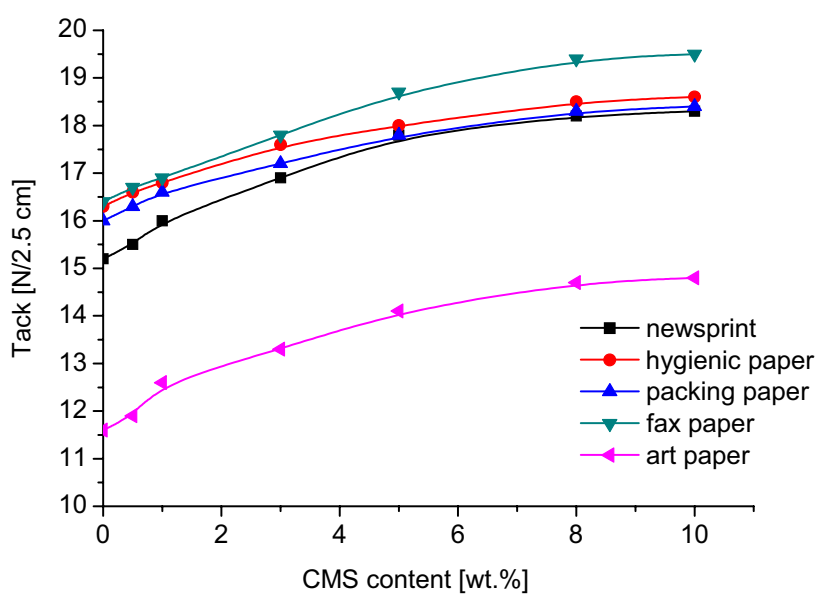

Fig. 1 Tack for various papers as a function of carboxymethyl starch concentration 
placed in a Miele washing machine with other test drapes until the washing machine is filled appropriately with garments. Prior to beginning a laundry cycle, each of the filters in the washing machine was checked and cleaned of any residue. The washing machine was set for a cycle of $60 \mathrm{~min}$. The water solubility time was evaluated visually. The laundry cycle include filling of water heated to $80^{\circ} \mathrm{C}$ and mixing with a commercially available detergent to create an aqueous alkali solution, followed by agitation in the soapy water, draining, rinsing, and spinning. After laundering, each of the drapes and the filters of the washing machine are examined for any adhesive or fibrous residue.

\section{Results and Discussion}

The tack of water-soluble self-adhesive splicing tapes containing carboxymethyl starch was tested using various papers types, such as newsprint, hygienic, packing, fax and art paper. As shown in Fig. 1, the tack of developed water-soluble tapes evaluated on selected papers increased with CMS content in the PSA system. For $10 \mathrm{wt} \%$ CMS content tack determined on newsprint, hygienic, and packaging paper had similar value of ca. $18.3 \mathrm{~N} / 2.5 \mathrm{~cm}$. The highest value of this parameter was noted for fax paper, and the lowest one for art paper: ca. 19.5 and $14.7 \mathrm{~N} / 2.5 \mathrm{~cm}$, respectively. The beneficial effect of CMS presence could be the result of hydrogen bonds formed between carboxylic groups of acrylic polymer and hydroxyl as well as carboxylic groups of polysaccharide derivative. It is known that physical crosslinking via hydrogen bonds chain beneficially affected tack as well as shear strength properties [6].

The formation of the interpolymer complexes by hydrogen bonds between native starch and PAA has been

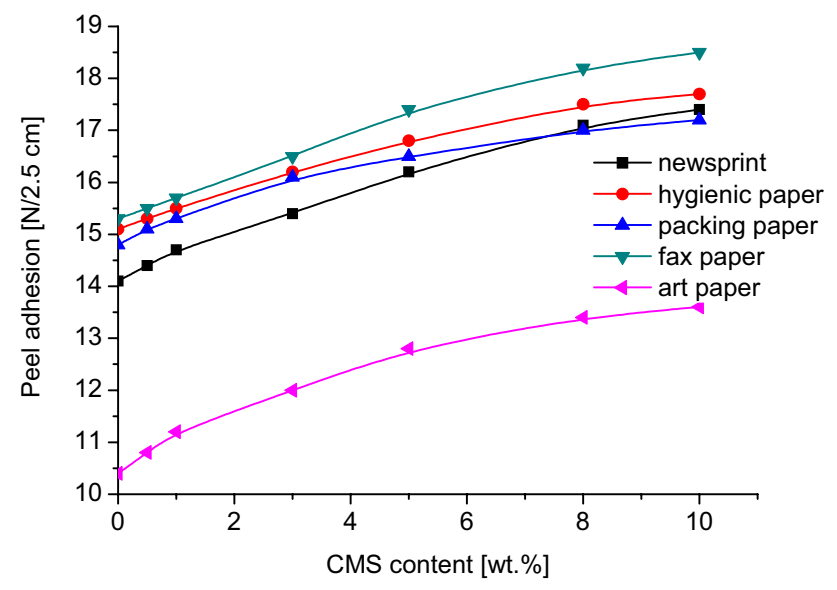

Fig. 2 Peel adhesion for various papers as a function of CMS content

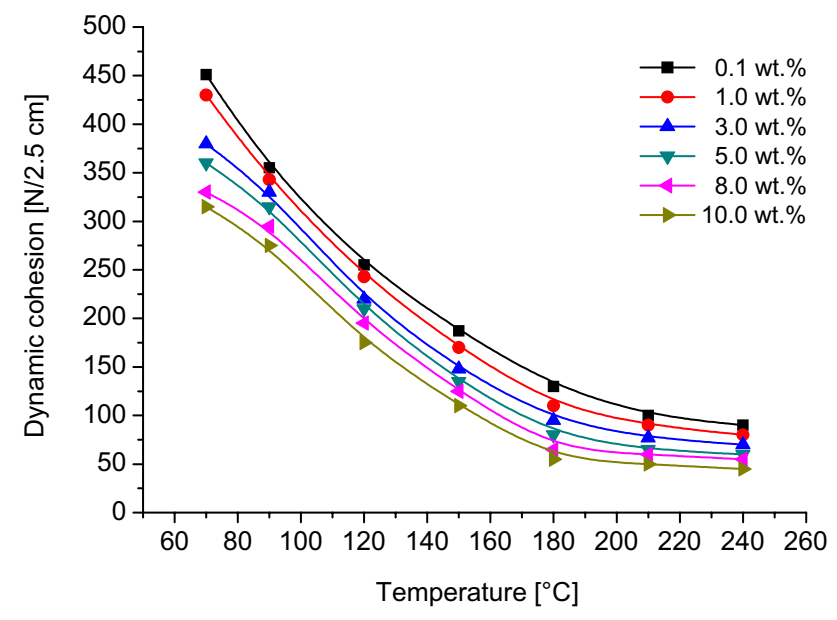

Fig. 3 Dynamic cohesion of tested water-soluble PSA containing various amount of CMS

reported [21]. However, applying in this work carboxymethylated starch was beneficial because of its higher adhesiveness as well as lower tendency to retrogradation than native starch [13].

The peel adhesion of water-soluble PSA tapes onto various paper types, such as newsprint, hygienic paper, packing paper, fax paper and art paper (Fig. 2) was measured after 20 min contact time with paper surfaces. The testing of peel adhesion of water-soluble self-adhesive tapes revealed that with increasing CMS content the peel adhesion values increased, and within the same paper groups ranged from 10.4 to $13.5 \mathrm{~N} / 2.5 \mathrm{~cm}$ for art paper, from 14.2 to $17.2 \mathrm{~N} / 2.5 \mathrm{~cm}$ for newsprint paper, from 14.8 to $16.8 \mathrm{~N} / 2.5 \mathrm{~cm}$ for packing paper, from 15.3 to $18.5 \mathrm{~N} / 2.5 \mathrm{~cm}$ for fax paper and from 15.2 to $17.3 \mathrm{~N}$ for hygienic paper (Fig. 2). This is probably dependent on paper moisture which can influence the adhesion to the above mentioned paper surfaces. Moreover, art paper is additionally coated to get smooth and glossy finish [22], that could additionally resulted in lower peel adhesion value when compared to the other paper types.

Table 3 Water-solubility time of modified water-soluble acrylic PSA containing CMS at different $\mathrm{pH}$-values

\begin{tabular}{llll}
\hline $\begin{array}{l}\text { CMS content in PSA } \\
{[\mathrm{wt} \%]}\end{array}$ & \multicolumn{3}{l}{ Solubility in water [s] } \\
\cline { 2 - 4 } & $\mathrm{pH} \mathrm{7}$ & $\mathrm{pH} \mathrm{9}$ & $\mathrm{pH} \mathrm{11}$ \\
\hline 0.1 & 205 & 174 & 153 \\
1 & 210 & 186 & 161 \\
3 & 222 & 196 & 170 \\
5 & 236 & 211 & 187 \\
8 & 254 & 228 & 201 \\
10 & 272 & 239 & 214 \\
\hline
\end{tabular}


In Fig. 3 the dynamic shear strength of water-soluble PSA tapes containing different concentration of carboxymethyl starch derivatives tested on steel at temperature range between 70 and $240^{\circ} \mathrm{C}$ was presented. The greatest reduction of dynamic cohesion was observed for the PSA systems containing the lowest CMS contents $(0.1$ and $1 \mathrm{wt} \%$ ), i.e. from ca. 450 to ca. $100 \mathrm{~N} / 2.5 \mathrm{~cm}$, at 70 and $240^{\circ} \mathrm{C}$, respectively. The best thermal performance evaluated as dynamic cohesion as a function of temperature was observed for water-soluble PSA with $10 \mathrm{wt} \% \mathrm{CMS}$, i.e. from ca. 325 to ca. $70 \mathrm{~N} / 2.5 \mathrm{~cm}$, in the same temperature range. The temperature increase caused enhanced mobility of both acrylic as well as polysaccharide derivatives chains. However, higher density of hydrogen bond formed between acrylic and modified starch molecules resulted in lower reduction of dynamic cohesion in case of PSA system containing the highest CMS amount. These data correlate with tack testing results.

In Table 3 the water-solubility time of developed PSA was presented. Generally, PSA modified with carboxymethyl starch derivatives were completely water-soluble and special paper was water dispersible. The water-solubility time values were very short and regardless the $\mathrm{pH}$ value and CMS content did not exceed 5 min. It increased with CMS content in PSA (e.g. from 153 up to 214 for $\mathrm{pH} 11$ ) and decreased with increasing $\mathrm{pH}$ value (e.g. from 272 to $214 \mathrm{~s}$ for $10 \mathrm{wt} \%$ ). It is known that protonated CMS exhibited reduced solubility in water [23]. The increase of $\mathrm{pH}$ value allowed for at least partial neutralization of carboxylic groups onto polymer chain and thus enhancing the solubility in water. On the other hand the increase of PSA water-solubility time with CMS content could be explained by high molecular weight of amylopectin. Potato starch (raw material for CMS production) contains about $20 \mathrm{wt} \%$ of lower molecular weight linear polymer, i.e. amylose, and the majority is amylopectin with molecular weight up to $440 \times 10^{6} \mathrm{Da}$ [24]. For comparison the $\mathrm{M}_{\mathrm{w}}$ of acrylic polymer in PSA was $711 \times 10^{3}$ Da (Table 2 ).

\section{Conclusions}

Novel water-soluble pressure-sensitive adhesives based on PAA and carboxymethyl starch have been prepared. For all paper types tested tack and peel adhesion values increased with CMS content (0.1-10 wt\% in PSA). The highest values of mentioned parameters were noted for $10 \mathrm{wt} \% \mathrm{CMS}$ content evaluated on fax paper, i.e. $19.5 \mathrm{~N} / 2.5 \mathrm{~cm}$ and $18.5 \mathrm{~N} / 2.5 \mathrm{~cm}$, respectively. The same system exhibited the lowest dynamic cohesion reduction (from ca. 325 to ca. $70 \mathrm{~N} / 2.5 \mathrm{~cm}$ ) measured in a temperature range $70-240{ }^{\circ} \mathrm{C}$.
Obtained PSA systems were completely soluble in water, and the time of water-solubility depended on $\mathrm{pH}$ value and varied between 153 and 272 s. Additional benefit would be replacing a part of synthetic petroleum based acrylic with low-cost modified natural polymer. Bearing in mind the above mentioned results proposed pressure-sensitive adhesive could successfully find application in paper industry for double-sided splicing tapes.

Open Access This article is distributed under the terms of the Creative Commons Attribution 4.0 International License (http:// creativecommons.org/licenses/by/4.0/), which permits unrestricted use, distribution, and reproduction in any medium, provided you give appropriate credit to the original author(s) and the source, provide a link to the Creative Commons license, and indicate if changes were made.

\section{References}

1. Dunn DJ (2003) In: Adhesives and sealants - technology, application and market. Rapra Technology Limited, Shawbury, pp 43-55

2. Minghetti P, Cilurzo F, Tosi L, Casiraghi A, Montanari L (2003) AAPS PharmSciTech 4:1

3. Czech Z, Pełech R, Butwin A (2008) Czasopismo Techniczne Chemia 2:293

4. Yan Z, Deng Y (2003) J Appl Polym Sci 90:1624

5. Yan Z, Luo Y, Deng Y, Schork J (2004) J Appl Polym Sci 91:347

6. Czech Z (2003) Polym Int 52:347

7. Wilpiszewska K, Czech Z (2014) Starch 66:660

8. Czech Z, Wilpiszewska K, Tyliszczak B, Jiang X, Bai Y, Shao L (2013) Int J Adhes Adhes 44:195

9. Yang L, Liu J, Du C, Qiang Y (2013) Adv J Food Sci Technol 5:1068

10. Wang Z, Li Z, Gu Z, Hong Y, Cheng L (2012) Carbohyd Polym 88:699

11. Imam SH, Gordon SH, Mao L, Chen L (2001). Polym Degrad Stabil 73:529

12. Tan H, Zhang Y, Weng X (2011) Procedia Eng 15:1171

13. Spychaj T, Wilpiszewska K, Zdanowicz M (2013) Starch 65:22

14. Das D, Jha S, Kumar KJ (2015) Int J Biol Macromol 77:181

15. Zhou X, Yang J, Qu G (2007) J Mater Process Technol 183:407

16. Zhou X, Yang J, Qian F, Qu G (2010) J Appl Polym Sci 116:2893

17. Zhang Y, Li L (2014) Comp Model New Technol 18:1150

18. Qiao Z, Gu J, Zuo Y, Tan H, Zhang Y (2014) Bioresources 9:6117

19. Pigłowski J, Kozłowski M (1985) Rheol Acta 24:519

20. Spychaj T, Zdanowicz M, Kujawa J, Schmidt B (2013) Polimery 58:503

21. Biswas A, Willet JL, Gordon SH, Finkenstadt VL, Cheng HN (2006) Carbohyd Polym 65:397

22. Liu PT, Liu XS, Liu JG (2013) Adv Mater Res 750-752:2040

23. Assaad E, Mateescu MA (2010) Int J Pharmac 394:75

24. Young AH (1984) In: Whistler RL, BeMiller JN, Paschall EF (eds) Starch: chemistry and technology. Academic Press, San Diego, pp 249-284 